\title{
Is social capital green? Cultural features and environmental performance in the European Union
}

\author{
Jesús Peiró-Palomino ${ }^{a,+}$ \\ Andrés J. Picazo-Tadeo ${ }^{b}$ \\ ${ }^{a}$ Department of Economics and INTECO Joint Research Unit, University Jaume I \\ ${ }^{\mathrm{b}}$ Department of Applied Economics II and INTECO Joint Research Unit, University of Valencia
}

${ }^{\mathrm{a},+}$ Corresponding author: Department of Economics, University Jaume I, Campus del Riu Sec, Avda. Vicent Sos Baynat s/n, 12006, Castelló de la Plana (Spain). Email: peiroj@uji.es

\footnotetext{
${ }^{\mathrm{b}}$ Department of Applied Economics II, University of Valencia, Avda. dels Tarongers s/n, E-46071, Valencia (Spain). Email: Andres.J.Picazo@uv.es
}

ABSTRACT. This paper analyses the relationship between social capital and environmental performance in the European Union. In a first stage, environmental performance is measured by an index of eco-efficiency at the country level, computed using Data Envelopment Analysis (DEA) techniques and data for the year 2013. In a second stage, the influence of social capital and other relevant control variables on eco-efficiency is assessed by means of truncated regressions and bootstrapping, as proposed by Simar and Wilson (2007). For several model specifications, tests fail to reject the hypothesis of no effect of social capital on environmental performance, and the main driver of environmental performance is found to be the level of economic development, measured by GDP per capita. Furthermore, this result is robust to different definitions of social capital and sample periods.

KEY WORDS: Environmental performance; European Union; Social capital.

JEL CLASSIFICATION: C61; Q5; Z10 


\section{INTRODUCTION AND MOTIVATION}

The concept of social capital has attracted the interest of economists, sociologists and policymakers. According to the OECD (2001), social capital is defined as 'networks together with shared norms, values and understandings that facilitate cooperation within and among groups'. Unfortunately, its multifaceted nature has resulted in a wide range of definitions and measures in the literature, with no academic consensus (see, for a review, Svendsen and Svendsen, 2009). A point of agreement, however, is the positive link between social and economic phenomena, formally established by Putnam (1993) and Knack and Keefer (1997), although related contributions can be found as far back as Hanifan (1916).

The seminal findings of all above-mentioned authors are supported by a long list of subsequent studies including Zak and Knack (2001), Beugelsdijk and Van Schaik (2005), Roth (2009), Bjørnskov (2012), Forte et al. (2015) or Peiró-Palomino (2016). It is argued that social capital reduces transaction costs and facilitates cooperation, mitigating monitoring costs and reducing information asymmetries (Knack and Keefer, 1997). These benefits translate into higher aggregate output and larger and sustainable welfare states (Bergh and Bjørnskov, 2011), boosted by a number of transmission mechanisms including human capital (Bjørnskov, 2009), physical capital investment (Dearmon and Grier, 2011; Peiró-Palomino and Tortosa-Ausina, 2015), financial development (Guiso et al., 2004), innovation (Akçomak and Ter Weel, 2009) and institutional quality (Bjørnskov and Méon, 2013).

To that extensive list, the preservation of the environment (Pretty and Ward, 2001; Pretty, 2003) can also be added. Social capital is expected to increase collaboration and engagement within the community, leading to a greater sense of collectivism and willingness to protect the natural resources, which are a public good. Moreover, if an individual cooperates in a high 
social capital environment, he or she will expect similar behaviour from his or her peers. ${ }^{1}$ Jones (2010) positively related social capital to the degree of achievement of environmental targets, since social capital is linked to the individual perceived costs and benefits of environmental policies. Halkos and Jones (2012) concluded that people are generally reluctant to pay environmental taxes to the State because they believe that these taxes will not be managed efficiently. ${ }^{2}$ However, they also found that some forms of social capital, in particular social norms and trust, are positively associated with willingness to pay. Similarly, where social capital abounds, citizens will also be more inclined to protect the environment, since they might expect similar behaviour from their peers. Polyzou et al. (2011) reported comparable results for the case of improvements in the quality of water, as did Liu et al. (2014) for the case of proenvironmental behaviour of residents in ecotourism destinations or Czajkowski et al. (2017) for the case of recycling decisions.

Furthermore, in a recent paper, Kountouris and Remoundou (2016) found that national culture is a significant determinant of individual environmental preferences, whereas Ingold (2017) showed how network structures enhance the building of social capital in climate adaptation policies. Social capital might also affect environmental behaviour through the quality

\footnotetext{
1 As argued by Torsvik (2000), social capital might, in the long term, facilitate cooperative solutions in Prisoner's Dilemma contexts. In the iterated version of the game (where the game is played repeatedly by the same prisoners), players prefer cooperation because the long-term benefits of that choice are considerably higher than the short-term advantages obtained by deviating from the cooperative solution. The cost for free-riders is high, since they are no longer trusted and cannot gain from future benefits, i.e. they are excluded.

2 This idea is expected to be connected with the quality of the government. In high social capital societies, politicians and government officials are likely to be more trustworthy and less prone to taking advantage of their positions for personal benefit. Moreover, according to Boix and Posner (1998), social capital generates societies better able and more willing to monitor public officials. They also suggest that social capital might help in striking deals, since it allows political promises that include payoffs to be effective in future periods.
} 
of government, the institutional framework and corruption levels. ${ }^{3}$ Fredriksson et al. (2004) found for a sample of OECD countries a negative association between corruption and energy policy outcomes. The intrinsic mechanisms behind these effects are the incentives of particular lobbies to offer bribes, their ability to coordinate bribery and the government's willingness to accept them. Following Fredriksson et al. (2005), environmental policy stringency is related to some forms of social capital, such as political participation, and to the existence of environmental lobbies in the form of associations. Empirical evidence has also highlighted positive links between social capital and education (Bjørnskov, 2009), political rights and civil liberties (Paxon, 2002), which, according to Torras and Boyce (1998), have a strong effect on environmental quality. However, Grafton and Knowles (2004) found no significant causality between a wide variety of social capital elements and environmental quality indicators, although they acknowledged the complexity of social capital and called for further research.

Related literature has also included social capital in environment Kuznets curves (EKC). ${ }^{4} \mathrm{Au}-$ thors such as Paudel and Schafer (2009), Keene and Deller (2013) and Ibrahim and Law (2014) found social capital to be associated with lower emissions of contaminants and with downwards shifts of the EKC. The threshold point in the curves also increases for countries that are rich in social capital. Other contributions including Dutt (2009), Leitão (2010), Park et al. (2007), Peng and Li (2009), Onel and Murherjee (2014) and Disli et al. (2016) also highlighted the influence of social and cultural values on the EKC relationship, suggesting that social features

\footnotetext{
${ }^{3}$ Similarly, the literature on social capital and economic growth suggests that a large part of the positive effects of social capital on productivity are channelled through institutional quality (Bjørnskov and Méon, 2015).

${ }^{4}$ According to the EKC framework, environmental degradation initially gets worse as a country develops economically. Then, after a given threshold is reached, the impact on the environment decreases, displaying an inverted U-shaped-relationship between environmental impact and economic development.
} 
might be a valuable tool for reducing environmental degradation in the medium- and longrun. ${ }^{5}$

Against this background, this paper analyses the relationship between social capital and environmental performance in the European Union (EU). Since 1973, the protection of the environment has been on the EU's policy agenda. The driven principles of the EU's environmental policy are based on the articles 11, and 191 to 193 of the Treaty on the Functioning of the European Unión (EU, 2012). The current guidelines that form part of the Horizon 2020 Strategy (H2020) summarise the targets and actions to be taken to achieve smart, sustainable and inclusive growth by year 2020. In particular, one of the H2020 guidelines concerns 'climate action, environment, resource efficiency and raw materials'. It promotes European competitiveness, raw materials security and citizens' well-being, while still protecting ecosystems and ensuring sustainability. Furthermore, environmental issues such as the greenhouse gas emissions responsible for global warming and climate change, the acidification of forests, lakes and freshwater systems, or the adverse effects on human health of particulate formation - mainly from the burning of fossil fuels - are currently major concerns for European policymakers, citizens and society as a whole.

As to the methodology, an indicator of eco-efficiency to measure environmental performance is computed in a first stage using Data Envelopment Analysis (DEA) techniques (Charnes et al., 1978). In a second stage, the influence of social capital on eco-efficiency - in addition to the effect of a number of other control variables - is assessed by means of truncated regressions and bootstrapping, as proposed by Simar and Wilson (2007). Unlike previous studies in this field of research, which have mostly linked social capital to simple measures of emissions, or

\footnotetext{
${ }^{5}$ Unfortunately, the nature of social capital, deeply ingrained in societies and stable over time, limits its use as a short-run instrument.
} 
to the adoption of individual eco-friendly behaviours (see, for a survey, Farrow et al., 2017), we approach environmental performance through the concept of eco-efficiency, which jointly accounts for both economic and ecological issues. ${ }^{6}$

According to the OECD (1998), eco-efficiency is defined as 'the efficiency with which ecological resources are used to meet human needs'. Therefore, it can be understood as the capacity of a given economy, or an agent in that economy - for instance, a firm - to produce a given quantity of goods and services with the minimum environmental damage. In this line of research, Camarero et al. $(2013,2014)$ computed eco-efficiency scores for the European and the OECD countries, finding that economies tend to converge into clubs of similar eco-efficiency scores. However, no explanation is given on the determinants of these scores. Therefore, in contrast to most of the previous works on social capital and the environment, which are micro-level studies, our approach takes a macro perspective, more aligned with the literature on social capital and development and with country-level environmental performance. Given that social capital might affect eco-efficiency by both boosting economic activity and promoting proecological actions - i.e., adopting greener technologies -, it seems natural to evaluate whether empirical evidence supports the theoretical arguments or, conversely, if the causal arrows between cultural features and environmental performance are more ambiguous.

\footnotetext{
${ }^{6}$ In this regard, several institutions and international organisations are calling for empirical evidence from robust environmental indicators that combine ecological and economic facets of production processes. For instance, the United Nations acknowledges that 'Making the concept of green growth operational for public policies requires a measurement that would capture the pattern of the quality of economic growth over time... Without indicators or a conceptual framework to guide policymakers, green growth as a paradigm shift in policymaking would prove an elusive goal.' (UN, 2009; p.3). Moreover, the European Environment Agency has recently pointed out that 'Environmental indicators are essential tools for assessing environmental trends, tracking progress against objectives and targets, evaluating the effectiveness of policies and communicating complex phenomena to non-technical audiences.' (EEA, 2014; p.5).
} 
The remainder of the paper is organised as follows. Section 2 describes the data and variables. Section 3 introduces the methodology, and the results are presented Section 4 . The final Section summarises and concludes.

\section{SAMPLE, VARIABLES AND SOURCES}

In order to assess the environmental performance of the members of the EU-287, we employ both economic and ecological variables to build an indicator of eco-efficiency. In addition, we consider a set of second-stage variables aimed at explaining eco-efficiency; these include information relative to countries' social capital endowment, our main variable of interest, as well as their environmental policy, legal and economic context and level of development.

\subsection{Environmental performance variables}

Environmental performance is assessed using data on gross domestic product (GDP) and emissions of a series of pollutants at the country level in $2013 .{ }^{8}$ The GDP data is intended to account for countries' economic performance and is measured in constant 2011 \$US in purchasing power parity (PPP) terms, with data from the World Development Indicators database of the World Bank. ${ }^{9}$ On the other hand, the data on emissions of 12 contaminants account for the ecological performance of the EU-28 members. These contaminants include carbon dioxide $\left(\mathrm{CO}_{2}\right)$, nitrous oxide $\left(\mathrm{N}_{2} \mathrm{O}\right)$, methane $\left(\mathrm{CH}_{4}\right)$, sulphur hexafluoride $\left(\mathrm{SF}_{6}\right)$, hydrofluorocarbons

\footnotetext{
7 The members of the EU-28 are Austria, Belgium, Denmark, Finland, France, Germany, Greece, Ireland, Italy, Luxembourg, Portugal, Spain, Sweden, the Netherlands, the United Kingdom - all of which were members of the former EU-15 -, in addition to Bulgaria, Croatia, Cyprus, the Czech Republic, Estonia, Hungary, Latvia, Lithuania, Malta, Poland, Romania, Slovakia and Slovenia - mainly countries from Central and Eastern Europe that entered the EU-28 from 2004 onwards.

${ }^{8}$ In order to account for the effect of possible measurement errors and/or abnormal observations, the data have in fact been computed as the averages for the years 2012 and 2013. Nevertheless, for the sake of simplicity, throughout the paper we refer to the sample period as 2013.

${ }_{9}^{9}$ The data were accessed on 21st April 2016 at http:/ / data.worldbank.org.
} 
(HFCs), perfluorocarbons (PFCs) - all of which are responsible for greenhouse gas (GHG) formation -, as well as non-methane volatile organic components (NMVOC), carbon monoxide (CO), nitrogen oxides $\left(\mathrm{NO}_{\mathrm{x}}\right)$, ammonia $\left(\mathrm{NH}_{3}\right)$, sulphur dioxide $\left(\mathrm{SO}_{2}\right)$ and, lastly, primary particulate matter (PM10). The sources for the data on these contaminants are the European Greenhouse Gases Inventory for emissions involved in the formation of greenhouse gases (GHGs), and the National emissions reported to the Convention on Long-range Transboundary Air Pollution (LRTAP Convention) for the remaining pollutants, with both of these datasets provided by the European Environment Agency (EEA). ${ }^{10}$

Following recent papers in this field of research (Kortelainen, 2008; Picazo-Tadeo et al., 2014; Beltrán-Esteve and Picazo-Tadeo, 2015), figures on the above-mentioned contaminants have been aggregated into four environmental pressures: i) global warming potential (GWP); ii) tropospheric ozone formation potential (TOFP); iii) acidification potential (ACIDP); and iv) particulate formation potential (PFP). ${ }^{11}$ While aggregate GHG emissions causing GWP have been obtained directly from the EEA, the remaining pressures have been calculated using conversion factors from the environmental assessment literature (De Leeuw, 2002). These factors are detailed in Appendix 1. One advantage of using pressures in our analysis is that, unlike particular contaminants themselves, environmental pressures represent current concerns for society. ${ }^{12}$ Furthermore, aggregating individual contaminants into environmental pressures

\footnotetext{
10 These datasets were accessed on 21 ${ }^{\text {st }}$ April 2016 at http:/ / www.eea.europa.eu.

${ }^{11}$ It is worth noting that some pollutants might cause more than one environmental pressure; furthermore, our environmental pressures represent potential rather than actual environmental impacts.

12 The pressures on the environment linked to economic activity have long been a matter of concern for European scientists and policymakers (EEA, 1995). In particular, global warming and climate change lead to wide-level changes in the atmosphere that put people at high risk and result in substantial costs for society. The rise in the tropospheric ozone level is also a matter of concern because of its adverse consequences on human health, ecosystems, agricultural crops and materials. Acidification is a transboundary problem that causes changes to the chemical composition of soils and freshwater systems, provoking the decline of forests
} 
greatly increases the discriminating power of our DEA-based models, thus yielding a more reliable assessment of environmental performance (see Cooper et al., 2007). Table 1 displays some descriptive statistics for GDP, the environmental pressures in the EU-28 and the secondstage variables introduced in the next Section. A complete description of all the variables used in the analysis and their sources can be found in Appendix 2.

\section{[Please, insert Table 1 around here]}

\subsection{Second-stage variables}

Our second-stage variables are intended to account for the determinants of environmental performance, and they are classified into three main groups: i) social capital, for which the variables are based on Bjørnskov (2006a) and Forte et al. (2015); ii) environmental policy; and iii) legal and economic context, for which the variables are taken from Esty and Porter (2005). For each group, we have constructed an aggregate index using factor analysis. In addition, to control for countries' level of development, GDP per capita and its squared have also been considered as additional explanatory variables; finally, we also control for the sectoral composition of economic activity through the share of manufacturing in Gross Value Added (GVA).

\section{Social capital}

Three social capital elements are considered in our research, namely, social trust, associational activity and the quality of civic norms. The data on these are taken from the European Values Study (EVS), which was carried out in four waves corresponding to the years 1981, 1990, 1999 and 2008. As we study eco-efficiency for the year 2013, we have taken data from the 2008 EVS,

and lakes. Lastly, particulates have adverse effects on human health, including cancer, damage to lung tissue or even premature death. 
conducted during the period 2008-10. In each country, about 1,500 interviewees were randomly selected in such a way as to ensure representativeness and cross-country comparability. The use of this dataset is common practice in the literature of social capital in Europe (see, for instance, Beugelsdijk and Van Schaik, 2005; Peiró-Palomino, 2016). The social capital data are from a period prior to the year considered for our response variable, which alleviates reverse causality problems. In any case, this is not the greatest concern in social capital studies, since there is abundant literature supporting the notion that social values remain highly stable over time.

In this respect, most previous research has focused on justifying the stability of social trust the most widely-used indicator of social capital in empirical papers -, although similar arguments may apply to other social capital dimensions, which include a number of deeply-ingrained cultural threats and social values. Uslaner (2008) found that current trust levels reported by descendants of immigrants to the US are highly correlated with those in their ancestors' countries of origin. Also, Nunn and Wantchekon (2011) identified high persistence in cultural features and individual beliefs, finding that current low trust levels in African economies have their origin in the transatlantic and Indian Ocean slave trade that took place a century ago. Tabellini (2008) stressed the influence of institutions in the distant past and political history in modelling current social values. Similarly, and based on Putnam's (1993) findings, Guiso et al. (2008) proposed a model to explain the intergenerational transmission of social beliefs that could account for the disparities that have persisted for more than 500 years across the Italian regions. Previously, Bjørnskov (2006b) had already reported high persistence in trust scores across different World Values Survey waves, concluding that variations fluctuate around stable levels and that trust in people shows a negligible reaction to a wide variety of changes, whether unexpected events or planned policy shifts. Rainer and Siedler (2009) and Heineck and Süssmuth (2013) reported similar results, finding that social trust remains stable 
even after radical political and institutional changes such as the German reunification process. More recently, Geys and Qari (2017) found that terrorist incidents have only a transitory effect on individuals' social trust; after a short period of time (as little as a few weeks) trust levels return to their long-run equilibrium.

Furthermore, the stability argument is important when establishing causality between social capital and other phenomena such as economic and institutional performance (see Bjørnskov, 2012; Bjørnskov \& Méon, 2013; 2015; Peiró-Palomino, 2016, to name a few recent contributions), which might also prevent endogeneity problems due to reverse causality. Accordingly, by the same token, we can expect low variation across EVS waves, and the data collected from the 2008 EVS can be considered as representative in our analysis of the relationship between environmental performance and social capital.

Beyond the above-mentioned arguments regarding the stability of social capital over time, in the EVS social trust is measured as the percentage of affirmative answers given when interviewees are asked if they, generally speaking, trust others. Active associational activity is a general indicator of the degree of collectiveness and the tendency to join and participate in associations. It is measured as the percentage of respondents who voluntarily participate in a wide range of associations. Finally, the civic norms indicator measures to what extent the following four actions are justified: (i) claiming state benefits to which one is not entitled; (ii) cheating on tax; (iii) accepting a bribe; and (iv) avoiding paying a fare on public transport. The indicator is the average score of the respondents, which ranges from 1 (never justified) to 10 (always justified). For ease of interpretation, the resultant score was rescaled so that higher values corresponded to better scores. Table 2 provides disaggregated social capital information by country. As commented on above, the second-stage variables are aggregated into indexes using factorial analysis, the results of which are reported in Table 3. Regarding the 
social capital index, social trust and associational activity play an important role in the construction of the index, whereas civic norms are of lesser importance.

[Please, insert Tables 2 and 3 around here]

The computed index of social capital by country is displayed in Figure 1. It shows that Nordic countries, the Netherlands and Belgium have the highest levels. Germany, the UK, Ireland and Austria register medium-high levels, followed by Spain, Italy, the Czech Republic and Estonia. On the opposite end of the spectrum, Portugal, France, Greece and most of the excommunist countries that joined the European Union from 2004 onwards have medium-low and low scores. These results are in line with those in previous literature (see Paldam and Svendsen, 2001; Zukowski, 2007).

\section{[Please, insert Figure 1 around here]}

\section{Environmental policy}

Following Esty and Porter (2005), we include a set of variables describing the environmental policy at country level. It includes the stringency of the environmental regulation, the enforcement of environmental regulation and the number of environmental treaties ratified. Data on these three variables come from the Executive Opinion Survey carried out by the World Economic Forum (WEF). The first two variables, which are averages of the years 2011 and 2012, are measured on a scale of 1 to 7 , with higher values associated with better scores. The number of ratified treaties corresponds to the year 2012.

\section{Legal and economic context}

Esty and Porter (2005) also suggested the inclusion of a second set of variables related to the legal and the economic context. In this respect, we consider three measures from the Worldwide Governance Indicators (WGI), namely, government effectiveness, regulatory quality and control 
of corruption, which capture the legal setting and regulatory enforcement. These variables range from -2.5 to 2.5 , with higher scores being associated with a better legal environment. In addition, R\&D expenditure (in $€$ per inhabitant, with data from Eurostat) and the quality of the scientific institutions (measured on a scale of 1 to 7 , with data from the WEF), capture the quality of the scientific and technical infrastructure. All these variables are averages of the years 2012 and 2013.

\section{GDP per capita and sectoral composition}

Finally, as stated by Esty and Porter (2005), it is essential to consider the degree of development of the economies as an additional control. To this end, we include average GDP per capita in 2012 and 2013, which is expected to be highly correlated not only with environmental performance but also with the rest of the potential explanatory variables; also, GDP per capita squared has been included with the purpose of testing for possible non-linear effects of the level of development on environmental performance. Finally, the average 2012-13 share of GVA coming from manufacturing activities, which proxies countries' industry structures, has also been included as control.

\section{METHODOLOGICAL NOTES}

\subsection{Assessing environmental performance (eco-efficiency) using Data Envelopment Analysis}

The environmental performance of the EU-28 members is assessed, as outlined above, through the concept of eco-efficiency. Beyond the intuitive interpretation set out in the Introduction, here we borrow the formal definition of eco-efficiency proposed by Kuosmanen and Kortelainen (2005), as a ratio between an indicator of countries' economic performance -measured by their GDP - and a composite indicator of their ecological performance -measured, in this case, by the aggregate pressure exerted on the environment from global warming potential 
(GWP), tropospheric ozone formation potential (TOFP), acidification potential (ACIDP), and particulate formation potential (PFP). Considering environmental performance as a ratio between economic and ecological performance offers, in our opinion, the advantage of being straightforward and easy to interpret for policymakers and the general public. Formally, eco-efficiency (EEff) is defined as:

$$
\begin{aligned}
\text { Eco-efficiency }(\text { EEff }) & =\frac{\text { Economic performance }}{\text { Ecological performance (aggregate environmental pressure) }} \\
& =\frac{\mathrm{GDP}}{\mathrm{w}_{\mathrm{GWP}} \mathrm{GWP}+\mathrm{w}_{\mathrm{TOFP}} \mathrm{TOFP}+\mathrm{w}_{\mathrm{ACIDP}} \mathrm{ACIDP}+\mathrm{w}_{\mathrm{PFP}} \mathrm{PFP}}
\end{aligned}
$$

Eco-efficiency improves when countries' economic performance increases relative to their ecological performance; i.e., the pressure exerted on the environment as a result of economic activity. Furthermore, in building the aggregate environmental pressure in Equation 1, we follow the standard approach in this literature, consisting of taking a linear weighted average of the individual environmental pressures as an aggregating function, with $\mathrm{w}_{\mathrm{GDP}}, \mathrm{w}_{\mathrm{TOFP}}, \mathrm{w}_{\mathrm{ACIDP}}$

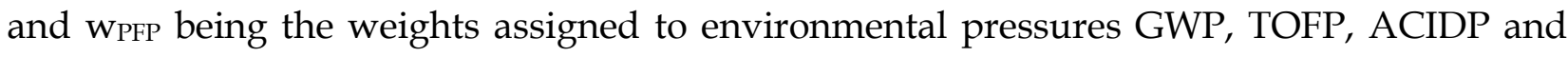
PFP, respectively. However, given that our environmental pressures have no market prices, there is no self-evident pattern for assigning these weights. While some researchers in this field have advocated using subjective weights based on expert opinion, following Kuosmanen and Kortelainen (2005) (also see Picazo-Tadeo et al., 2011), in this paper we have decided in favour of DEA as our preferred aggregating method.

DEA techniques are a widespread nonparametric approach to performance evaluation, which was initially proposed by Charnes et al. (1978) and has since been widely used in empirical papers (see Cook and Seiford, 2009; Emrouznejad and Yang, 2017). In essence, DEA enables 
the construction of a technological frontier from data on best observed practices within a sample of decision-making units, and the calculation of the relative position of each unit in the sample with respect to that frontier in terms of a performance indicator. In addition, a feature of DEA that is particularly useful for the purposes of our research is that the weights assigned to our environmental pressures are endogenously generated at country level using the benefitof-the-doubt principle (Cherchye et al., 2007). According to this principle, each country in the EU-28 would be assigned the set of weights that places it in the best position when compared to all other countries in the sample using the same combination of weights. Other features of DEA techniques are outlined in Cooper et al. (2007).

In order to obtain country-level eco-efficiency scores with DEA, let us assume that there is an underlying unknown environmental technology denoted by the pressure-generating technology set (PGTS), which represents all technologically feasible combinations of GDP and environmental pressures $(\mathrm{P})$, given the state-of-knowledge. Formally, the PGTS is defined as (Picazo-Tadeo et al., 2011):

PGTS $=\left[(G D P, P) \in \mathfrak{R}_{+}^{5} \mid\right.$ GDP can be obtained with pressures $\left.\mathrm{P}\right]$

Furthermore, it is assumed that this environmental technology features a number of properties suggested by Picazo-Tadeo et al. (2012; p.799). These properties include: i) economic activity necessarily generates pressures on the environment; ii) lower GDP can always be obtained with the same amount of environmental pressures; iii) pressures can always be increased for 
a given GDP; and, finally, iv) any convex combination of feasible or observed sets of GDP and environmental pressures is also feasible. ${ }^{13}$

Based on this characterisation of the environmental technology, computation of the eco-efficiency score of country c' belonging to the EU-28 requires solving the following programming problem (Kuosmanen and Kortelainen, 2005; also see Picazo-Tadeo et al., 2011):14

Maximise $_{\mathrm{w}_{\mathrm{GWP}}, \mathrm{w}_{\mathrm{TOFP}}, \mathrm{w}_{\mathrm{ACIDP}}, \mathrm{w}_{\mathrm{PFP}}}$ EEff $_{\mathrm{c}^{\prime}}=\frac{\mathrm{GDP}_{\mathrm{c}^{\prime}}}{\mathrm{w}_{\mathrm{GWP}} \mathrm{GWP}_{\mathrm{c}^{\prime}}+\mathrm{w}_{\mathrm{TOFP}} \mathrm{TOFP}_{\mathrm{c}^{\prime}}+\mathrm{w}_{\mathrm{ACIDP}} \mathrm{ACIDP}_{\mathrm{c}^{\prime}}+\mathrm{w}_{\mathrm{PFP}} \mathrm{PFP}_{\mathrm{c}^{\prime}}}$ subject to:

$$
\begin{aligned}
& \frac{\mathrm{GDP}_{\mathrm{c}}}{\mathrm{w}_{\mathrm{GWP}} \mathrm{GWP}_{\mathrm{c}}+\mathrm{w}_{\mathrm{TOFP}} \mathrm{TOFP}_{\mathrm{c}}+\mathrm{w}_{\mathrm{ACIDP}} \mathrm{ACIDP}_{\mathrm{c}}+\mathrm{w}_{\mathrm{PFP}} \mathrm{PFP}_{\mathrm{c}}} \quad 1 \quad \mathrm{c}=1, \ldots, 28 \\
& \mathrm{w}_{\mathrm{GWP}}, \mathrm{w}_{\text {TOFP }}, \mathrm{w}_{\mathrm{ACIDP}}, \mathrm{w}_{\mathrm{PFP}} 0
\end{aligned}
$$

The objective of this program is to find the set of non-negative weights for the environmental pressures that places country $c^{\prime}$ in the best position when it is compared with all other EU-28 countries in the sample using this set of weights; i.e., it maximises the eco-efficiency of this country subject to a normalisation restriction. This problem is, however, a computationally demanding fractional linear programming problem as the objective function and the set of

\footnotetext{
${ }^{13}$ Environmental pressures are, therefore, formally treated as conventional inputs in production processes, as many other papers in this literature have done, including Hailu and Veeman (2001), Korhonen and Luptacik (2004), Kuosmanen and Kortelainen (2005), Zhang et al. (2008) and Beltrán-Esteve and Picazo-Tadeo (2015). One convincing argument for doing so is that environmentally detrimental resultants from economic activity can be seen as the use of the environmental capacity required for their disposal (Considine and Larson, 2006; also see Cropper and Oates, 1992). A recent paper by Dakpo et al. (2016) highlights the main advantages and drawbacks of the different approaches followed in performance analyses to modelling environmental technologies.

${ }^{14}$ In this program, it is assumed that the environmental technology exhibits constant returns to scale (see Banker et al., 1984). Picazo-Tadeo et al., (2012; p.802) provide a detailed justification of this common assumption in the framework of environmental performance measurement.
} 
constraints in (i) are both nonlinear. Alternatively, Equation 3 has the following linear dual equivalent formulation (see Cooper et al., 2007):

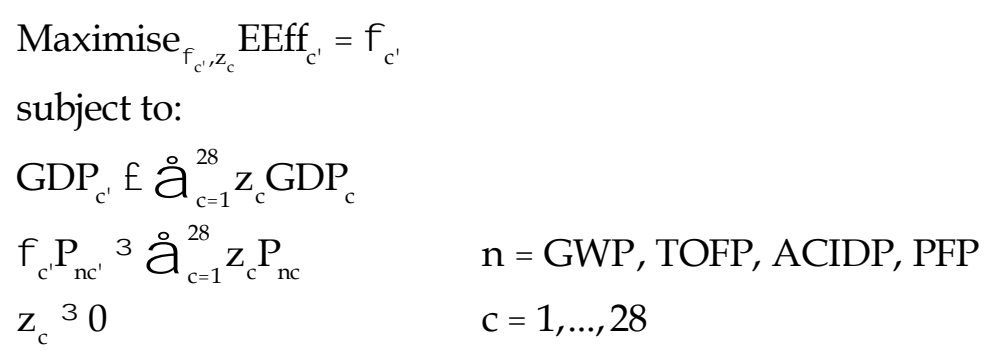

The scores of eco-efficiency obtained from Equation 4 are upper-bounded to one, a value that represents the best performance. Furthermore, the lower the score, the lower the level of ecoefficiency; e.g., an eco-efficiency score of, let us say, 0.8 for a given country would mean that said country could maintain its economic performance while generating only $80 \%$ of the pressures it currently exerts on the environment. ${ }^{15}$

\subsection{Second-stage analysis: the determinants of eco-efficiency}

DEA focuses on assessing performance, as described above, but it does not explain differences in performance between decision-making units. In the empirical literature, however, it has been common practice to carry out second-stage analyses aimed at investigating the determinants of performance. Our main interest in this paper is to explore whether the different endowments of social capital might explain differences in eco-efficiency between EU-28 countries. To this end, we adopt the approach suggested by Simar and Wilson (2007), based on truncated regression and bootstrapping techniques.

\footnotetext{
${ }^{15}$ Other indicators of eco-efficiency could also be computed using DEA techniques; e.g., measures of countries' performance in the management of specific environmental pressures (Picazo-Tadeo et al., 2012; Gómez-Limón et al., 2012; also see Wursthorn et al., 2011). However these computations are beyond the aim of this paper.
} 
This procedure allows us to account for the nature of our DEA-based scores of eco-efficiency and the unknown serial correlation between them. In essence, it requires simulating a sensible data-generating process, generating artificial bootstrap samples from this process, and building standard errors and confidence intervals for the parameters of interest through bootstrapping. According to the first algorithm proposed by Simar and Wilson (2007; pp.41-42), explaining the eco-efficiency of the EU-28 members in our case study would entail the following steps:

1. Compute a set of eco-efficiency scores for the EU-28 members using DEA, along the lines explained in Section 3.1.

2. Use maximum likelihood techniques to estimate the parameters $\beta$ and $\sigma_{\varepsilon}$ in the truncated regression of the eco-efficiency scores obtained in step 1 on a set of covariates $z$, using the subset of eco-inefficient countries; i.e., countries scores below one $\left(\hat{\mathrm{EEff}} \mathrm{c}_{\mathrm{c}}<1\right)$. Formally:

$\hat{\mathrm{EEff}}=\mathrm{z}_{\mathrm{c}}+_{c}$ ' with ${ }_{c}{ }_{c}{ }^{+}{ }_{c}$ and ${ }_{c} \quad \hat{E E f f}_{c}$ EEff $_{c}$

3. Loop over the following three steps L times to obtain a set of bootstrapped estimates of the parameters $\beta$ and $\sigma_{\varepsilon}$; namely, $B=\left[\left({ }^{\prime} \mathrm{b}, \wedge \mathrm{b}\right)\right]_{\mathrm{b}=1}^{\mathrm{L}}$

3.1. For each eco-inefficient country; i.e., with $\hat{E}_{E f f}<1$, draw ${ }_{c}^{b}$ from the following normal distribution:

$\mathrm{N}(0, \hat{\prime})$ right-truncated at point $\left(\begin{array}{lll}1 & & \\ & & \mathrm{z}_{\mathrm{c}}\end{array}\right)$

3.2. Compute $\operatorname{EEff}_{c}^{b}={ }^{\hat{}}{ }^{\prime} z_{c}+{ }_{c}^{b}$, again for eco-inefficient countries.

3.3. Estimate ${ }^{\hat{b}}$ and ${ }^{\wedge b}$ by truncated regression and maximum likelihood using the artificial eco-efficiency scores computed in step 3.2 as the dependent variable. 
4. Finally, use values in B and the original estimates to build a confidence interval for the parameters $\beta$ and $\sigma_{\varepsilon}$.

\section{RESULTS}

\subsection{Environmental performance assessment: scores of eco-efficiency}

The methods introduced in Section 3 have been implemented to compute, in the first place, eco-efficiency scores at the country level as defined in Equation 1.16,17 Considering GDP and the environmental pressures in each country, the weighted average ${ }^{18}$ for eco-efficiency is 0.781 , suggesting that the same level of GDP could be attained in the EU-28 while generating only 78.1 per cent of the pressures currently exerted on the environment; in other words, nearly 22 per cent of these pressures could be avoided by acting in an eco-efficient manner. In the countries of the former European Union-15 (EU-15), the weighted average is 0.828, indicating better performance in this group of economies than in members that joined the EU in the 2000s, which are mostly ex-communist countries from Eastern Europe.

\footnotetext{
16 To do so, we used DEA-Solver Pro7.0 software.

17 The optimal weights for the four environmental pressures considered in Equation 1 have a mathematical meaning in the context of our research, as explained in Section 3.1 (for more details see Cooper et al., 2007; p.25). Nonetheless, following the suggestion of one referee, we include here their computed values. Average weightings are $0.000014,0.004532,0.000825$ and 0.000000 for global warming potential, tropospheric ozone formation potential, acidification potential, and particulate formation potential, respectively. Furthermore, the pressures that make the greatest contribution to the aggregate environmental pressure - which depends on both their measurement units and their magnitude, as well as weightings - are tropospheric ozone formation potential and global warming potential, while the pressure that contributes the least is particulate formation potential, which always enters with zero weight in the construction of the aggregate pressure. Beyond these figures, weightings at the environmental pressure and country levels, as well as the contributions of each individual pressure to countries' aggregate environmental pressure, are available to readers on request.

${ }^{18}$ Computing weighted averages for the EU allows us to assign different importance to member countries according to their size; weightings have been calculated according to countries' GDP.
} 
Figure 2 provides a graphical illustration of eco-efficiency at the country level. The darkest colour corresponds to fully eco-efficient countries, i.e., with scores equal to one; the two countries registering this score are Sweden and the Netherlands. Eco-efficiency is relatively high (scores above 0.8) in most of the Central European countries, including France, Germany, the United Kingdom, Austria, Italy and Belgium. Southern European economies such as Greece, Portugal and Spain record the lowest levels of eco-efficiency within the EU-15 members, along with Finland and Denmark. Finally, the poorest environmental performance corresponds to most of the Eastern European countries that are the most recent members of the EU-28. Overall, these results are in line with those from other recent papers that have also assessed environmental performance in the European Union using different conceptual and methodological approaches; these include Kortelainen (2008), Camarero et al. (2013, 2014), Picazo-Tadeo et al. (2014) and Beltrán-Esteve and Picazo-Tadeo (2015). In our opinion, this makes our DEAbased assessment of environmental performance both credible and reliable.

\section{[Please, insert Figure 2 around here]}

Table 4 provides scores of Spearman's rank correlation between eco-efficiency and the secondstage variables considered in our analysis, including social capital variables, environmental policy variables and legal and economic context variables. With the exception of civic norms and environmental treaties ratification, in all cases the rho-statistic is significant at standard confidence levels. The highest correlations are found for the variables capturing the legal and economic context, especially for government effectiveness, control of corruption, R\&D expenditure and the quality of scientific institutions. The non-significant correlation found for civic norms is in line with the results reported by Forte et al. (2015), who found no links between this indicator and regional economic growth in the European context.

[Please, insert Table 4 around here] 


\subsection{Explaining eco-efficiency: Second-stage regression results}

Table 5 reports the results from the truncated regression for a variety of model specifications, where the aggregate indexes are included sequentially. ${ }^{19}$ For all models, 5,000 bootstrap replications have been performed and in all cases the dependent variables are our country-level eco-efficiency scores. Models 1, 2 and 3 include as explanatory variables the indexes of social capital, environmental policy and the legal and economic context, respectively. The results show a non-significant effect of social capital. In contrast, environmental policy and the legal and economic context indexes are both significant at the $1 \%$ level.

\section{[Please, insert Table 5 around here]}

When all three indexes are jointly included in Model 4, the only one that remains significant (at 5\% confidence level) is the legal and economic context, suggesting that the likely effect of environmental policy on eco-efficiency is indirectly channelled through legal and economic variables. ${ }^{20}$ Furthermore, it is also reasonable to expect that eco-efficiency is related to the degree of economic development. In order to control for this possibility, we run Model 5, which incorporates GDP per capita and its squared, in addition to the share of manufacturing in GVA, as additional explanatory variables of eco-efficiency. The estimated coefficient for the GDP per capita is positive and statistically significant at the $1 \%$ confidence level, while the parameter of its square is negative and also highly significant. Jointly considered, these results point to a positive but decreasing effect of GDP per capita on environmental performance.

\footnotetext{
${ }^{19}$ Estimations have been carried out with Stata 14 software, and the Stata module developed by Tauchmann (2016).

${ }^{20}$ In that regard, Bjørnskov and Meón (2015) showed that social capital effects -in particular social trust- on productivity are channelled via institutional quality; i.e., the statistical significance of trust in explaining productivity vanishes when institutional quality is included in the regressions. In our estimations, however, the social capital indicator is non-significant even when included as a single regressor, which suggests that it is unlikely that the quality of the legal and economic context is capturing social capital effects.
} 
Conversely, the estimated parameter for the share of manufacturing in GVA is not statistically significant. Furthermore, including GDP per capita and its squared has a great effect on the rest of the variables in the model since, as compared to Model 4, the legal and economic context index loses its significance in Model 5; that is, once GDP per capita is accounted for, no causal relationship is found regarding any of the three indexes and eco-efficiency.

This result might provide some evidence on the likelihood that the variables analysed exert an indirect effect on environmental performance through their effect on development, measured by GDP per capita. In particular, a more reliable legal framework and innovation-oriented policy that encourages knowledge endowments and high-quality research infrastructure might increase GDP per capita and, ultimately, these effects translate into better environmental performance.

Similar arguments are put forth by Bjørnskov and Méon (2013), who concluded that the effects of social trust - the most widely-used social capital indicator, as already mentioned - on economic growth are indirect; they are channelled through education and more reliable institutions, making it difficult to estimate the isolated effect of trust. In our case, the social capital index is non-significant even in Model 1, where the index is included separately from the others and there is no possibility that other variables such as GDP per capita, or even the legal and economic context and the environmental policy indexes are absorbing its effect. Therefore, our results suggest that there is no causal relationship between social capital and environmental performance. This finding departs from most of the previous literature on this topic, but it is aligned with Grafton and Knowles' (2004) results, indicating that higher levels of social capital and related variables are not necessarily linked to better levels of national environmental performance.

As a robustness check of our results, we have estimated Models 6 to 10 (see Table 6), where 
the eco-efficiency score remains as the dependent variable, and the explanatory variables are the residuals from four regressions of the social capital, environmental policy and legal and economic context indexes, as well as the share of manufacturing on GVA, on GDP per capita, respectively. These residuals account for the variance of these variables that is not associated with differences between countries in terms of GDP per capita; i.e., they are orthogonal to GDP per capita. Results from the first four models in Table 6 show that, beyond the constant, none of the estimated coefficients is statistically significant at standard confidence levels. Conversely, when GDP per capita and its square are included as additional regressors in Model 10, the estimated parameters associated with these two variables have the expected sign and are highly significant, indicating that differences in eco-efficiency among EU-28 members are explained by disparities in their degree of development. Furthermore, while Models 2 to 4 were globally significant at the standard confidence levels now, once our three indices and the share of manufacturing in GVA have been netted out from their correlation with GDP per capita, only Model 10 has global significance.

\section{[Please, insert Table 6 around here]}

A matter of concern with our results is that they are obtained in a cross-sectional setting. Accordingly, extending them over time largely relies on the assumption of stability of social capital. In this respect, it might be unwise to generalise our findings on the question of whether a relationship exists between social capital and environmental performance in the EU-28 on the basis of a single cross-section, particularly if social capital in the EVS is shown to be unstable over the years. ${ }^{21}$ To address this concern, we have compared the figures in the 2008 EVS

\footnotetext{
${ }^{21}$ As noted by one referee, the ideal scenario would be to use both spatial and longitudinal data in order to see whether there is any variation in the relationship between social capital and environmental performance across European countries and years. Although we agree with this appraisal, there are both practical and theoretical constraints on carrying out this kind of analysis in our case study. First, there are serious limitations regarding data availability; i.e., some of the datasets used in our research are not updated on a regular basis. And second, the temporal stability of social capital, as theoretically argued
} 
for the three dimensions included in our definition of social capital - social trust, association and civic norms - with those in the 1999 EVS. In doing so, we have first computed the Spearman's rank correlations reported in Table 7; all are positive, high - particularly in the case of social trust - and statistically significant at standard confidence levels. Furthermore, results from the Kolmogorov-Smirnov test (see Conover, 1999) fail to reject the hypothesis of equality of distributions in all three cases. Beyond the theoretical arguments set out in Section 2.2, these empirical results seem to support the temporal stability of the EVS social capital indicators in the EU-28 context.

\section{[Please, insert Table 7 around here]}

Additionally, we have attempted to go one step further by carrying out two final robustness checks on our results. On the one hand, we have re-estimated our Models 1, 4, 5, 6, 9 and 10, i.e., those involving the variable social capital, using figures on social trust, association and civic norms from the 1999 EVS, while keeping the remaining variables unchanged. ${ }^{22}$ The results for Models $1^{\prime}, 4^{\prime}$ and $5^{\prime}$ are included in Appendix 3, and they led to fairly similar conclusions to those already highlighted. In order words, the lack of statistical significance of the relationship between social capital and environmental performance in the EU-28 holds no matter which EVS wave the figures on social capital come from. Likewise, signs and statistical significance for the estimated parameters of the rest of variables also remain unchanged. Finally, results for Models 6', 9' and 10' estimated from the residuals with figures from the 1999

in Section 2.2 and later empirically confirmed in the case of the EVS, could make results from estimations with panel data difficult to interpret, as the effect of social capital is likely to be captured by country fixed effects (see Bjørnskov, 2012).

22 As compared with the use of a panel data analysis, we believe that the option of estimating our models with social capital figures from the 1999 EVS while keeping the remaining variables unaltered would also allow us to check the robustness of our results regarding the lack of a statistically significant relationship between social capital and environmental performance in the EU-28. Furthermore, estimations with data from the 1999 EVS have been carried out excluding Cyprus for reasons of data availability. 
EVS - which are not included in the paper, but are available to readers on request - are also consistent with our initial results using data from the 2008 EVS.

On the other hand, we have further checked the stability of social capital effects jointly with the way the concept of social capital is approached, i.e., the indicators selected to measure it. In doing so, we have also re-estimated our models using social trust as a single indicator of social capital, with data from both the 1999 and 2008 waves of the EVS. As explained in Section 2.2, and also mentioned later on, social trust is the indicator that has received most attention in the social capital literature. The results obtained for Models $1^{\prime \prime}, 4^{\prime \prime}$ and $5^{\prime \prime}$, which are in Appendix 4, are conclusive: once again, they clearly point to a non-significant relationship between social capital and environmental performance, regardless of which EVS wave the data on trust come from. The consistency of the results using trust instead of the composite social capital indicator again suggests that the legal and economic framework does not in fact transmit the effect of our variable of interest to environmental performance. Furthermore, the signs of the estimated coefficients for the remaining variables and their statistical significance are also unaltered, as they are the results from the residuals, available on request.

It is our belief that the results from these two final checks can be interpreted as additional proof of the robustness of our research. Put simply, the lack of statistical significance of the relationship between social capital and environmental performance in the EU-28 is a result that holds regardless of the definition of social capital - whether a composite index including social trust, association and civic norms indicators, or just the narrower concept of social trust - and the time period of the social capital data - whether the 2008 or 1999 EVS waves.

\section{SUMMARY AND DISCUSSION}

In this paper, we have investigated the relationship between social capital and environmental performance, measured in terms of eco-efficiency. While previous research in this field has 
only accounted for the environmental side of production processes using simple indicators of environmental performance, our research is, as far as we know, the first attempt to link social capital and a composite indicator of environmental performance that jointly accounts for both economic and ecological issues. As regards the methodology, we have first computed a set of eco-efficiency scores for the members of the EU-28 using Data Envelopment Analysis techniques; in a second-stage analysis, we have studied the determinants of these scores, including social capital and a variety of controls, using truncated regression and bootstrapping.

Our results are thought-provoking since, contrary to most of the previous empirical literature linking cultural and ecological issues, with the exception of Grafton and Knowles (2004), they led to reject a significant causal relationship between social capital and environmental performance. This result is robust across alternative model specifications with different control variables, different approaches to the concept of social capital, and different sample periods. However, the level of economic development, measured by GDP per capita, seems to be the major factor responsible for environmental performance. Once it is included, the rest of the variables lose their significance, although we cannot completely rule out the possibility that they affect eco-efficiency indirectly via GDP per capita.

It is also possible that the effects of social capital take place more locally. Contributions such as Peiró-Palomino and Tortosa-Ausina (2015) argued for the importance of social capital at the regional level, whereas others such as Westlund et al. (2014) maintained that the effects of social capital are seen even more locally, going down to more disaggregated levels of analysis such as villages or neighbourhoods. Unfortunately, data constraints arise for these smaller geographical levels. While it is possible to measure social capital at the individual level, ecoefficiency scores cannot be computed at these levels of analysis due to a lack of available data, especially on ecological impact. 
In any case, our results should be considered as a first attempt to assess the link between social capital and eco-efficiency. Accordingly, they involve a series of limitations that deserve more attention in future research. Apart from the need for more disaggregated analyses (regional/local), another potential issue to be explored is the possible existence of non-linearities and heterogeneous effects of social capital (see Peiró-Palomino, 2016), since its effects might vary with the geographical setting. In addition, efforts should be made to better understand the mechanisms operating between culture and environment. If we bear in mind that changes in social capital take place only in the long run - cultural aspects are stable over time -, this could shed some light on why certain countries register better ecological performance than others under a given policy framework. Accordingly, it seems crucial to gain a deeper understanding of the indirect effects of social capital, in particular those that are channelled through economic development. This will provide policymakers with valuable information for policy design in the years to come, when environmental performance will be of ever greater importance.

\section{ACKNOWLEDGEMENTS}

We gratefully acknowledge the thorough comments and suggestions received from the referees and the Editor. Furthermore, we appreciate the financial support from the Spanish Ministry of Economy and Competitiveness (projects ECO2014-55221-P and ECO2016-75237-R) and the Valencian government (project PROMETEOII/2014/053).

\section{REFERENCES}

Akçomak, I., Ter Weel, B. 2009. Social capital, innovation and growth: evidence from Europe. European Economic Review. 53, 544-567. 
Banker, R., Charnes, R., Cooper, W. 1984. Some models for estimating technical and scale inefficiencies in Data Envelopment Analysis. Management Science. 30, 1078-1092.

Beltrán-Esteve, M., Picazo-Tadeo, AJ. 2015. Assessing environmental performance trends in the transport industry: Eco-innovation or catching-up? Energy Economics. 51, 570-580.

Bergh, A., Bjørnskov, C. 2011. Historical trust levels predict the current size of the welfare state. Kyklos. 64(1), 1-19.

Beugelsdijk, S., Van Schaik, T. 2005. Social capital and growth in European regions: an empirical test. European Journal of Political Economy. 21(2), 301-324.

Bjørnskov, C. 2006a. The multiple facets of social capital. European Journal of Political Economy. 22(1), 22-40.

Bjørnskov, C. 2006b. Determinants of generalized trust: A cross-country comparison. Public Choice. 130, 1-21.

Bjørnskov, C. 2009. Social trust and the growth of schooling. Economics of Education Review. $28(2), 249-257$.

Bjørnskov, C. 2012. How does social trust affect economic growth? Southern Economic Journal. 78(4), 1346-1368.

Bjørnskov, C., Méon, PG. 2013. Is trust the missing root of institutions, education, and development? Public Choice 157, 641-669.

Bjørnskov, C., Méon, PG. 2015. The productivity of trust. World Development. 70, 317-331.

Boix, C., Posner, DN. 1998. Social capital: explaining its origins and effects on government performance. British Journal of Political Science. 28, 686-693.

Czajkowski, M., Hanley, N., Nyborg, K. 2017. Social norms, morals and self-interest as determinants of pro-environment behaviours: The case of household recycling. Environmental and Resource Economics. 66: 647-670

Camarero M., Castillo J., Picazo-Tadeo AJ., Tamarit C. 2013. Eco-efficiency and convergence in OECD countries. Environmental and Resource Economics. 55, 87-106.

Camarero M., Castillo J., Picazo-Tadeo AJ., Tamarit C. 2014. Is the eco-efficiency in greenhouse gas emissions converging among European Union countries? Empirical Economics. 47, 143-168.

Charnes, A., Cooper, WW., Rhodes, E. 1978. Measuring the efficiency of decision-making units. European Journal of Operational Research. 2, 429-444. 
Cherchye, L., Moesen, W., Rogge, N., van Puyenbroek, T. 2007. An introduction to 'benefit of the doubt' composite indicators. Social Indicators Research. 82(1), 111-145.

Conover, WJ. 1998. Practical nonparametric statistics. $3^{\text {rd }}$ Edition, West Sussex: John Wiley \& Sons, Inc.

Considine T., Larson D. 2006. The environment as a factor of production. Journal of Environmental Economics and Management. 52, 645-662.

Cook, WD., Seiford, LM. 2009. Data envelopment analysis (DEA) - thirty years on. European Journal of Operational Research. 192, 1-17.

Cooper, WW., Seiford, LM., Tone, K. 2007. Data Envelopment Analysis. A comprehensive text with models, applications, references and DEA-Solver software. Springer, New York.

Cropper M., Oates W. 1992. Environmental economics - A survey. Journal of Economic Literature. $30,675-740$.

Dakpo K., Jeanneauxc P., Latruffed L. 2016. Modelling pollution-generating technologies in performance benchmarking: Recent developments, limits and future prospects in the nonparametric framework. European Journal of Operational Research. 250, 347-359.

De Leeuw, FAAM. 2002. A set of emission indicators for long-range transboundary air pollution. Environmental Science and Policy 5, 135-145.

Dearmon, J., Grier, K. 2011. Trust and the accumulation of physical and human capital. European Journal of Political Economy. 27(3), 507-519.

Disli, M., Ng, A., Askari, H. 2016. Culture, income, and $\mathrm{CO}_{2}$ emission. Renewable and Sustainable Energy Reviews. 62, 418-428.

Dutt, K. 2009. Governance, institutions and the environment-income relationship: a crosscountry study. Environment, Development and Sustainability. 11, 705-723.

EEA (European Environment Agency) 1995. Europe's environment - The Dobris assessment. European Environment Agency, Luxembourg.

EEA (European Environment Agency) 2014. Digest of EEA Indicators 2014. Technical Report 8/2014. European Environment Agency, Luxembourg.

Esty, D., Porter, ME. 2005. National environmental performance: an empirical analysis of policy results and determinants. Environmental and Development Economics. 10(4), 391-434.

EU (European Union) 2012. Treaty on the Functioning of the European Union. Official Journal of the European Union. C326; 26 October 2012. 
Emrouznejad, A. Yang, G. 2017. A survey and analysis of the first 40 years of scholarly literature in DEA: 1978-2016. Socio-Economic Planning Sciences. In press (DOI 10.1016/ j.seps.2017.01.008.

Farrow, K., Grolleau, G., Ibanez, L. 2017. Social norms and pro-environmental behavior: A review of the evidence. Ecological Economics. 140, 1-13.

Forte, A., Peiró-Palomino, J., Tortosa-Ausina, E. 2015. Does social capital matter for European regional growth? European Economic Review. 77, 47-64.

Fredriksson, PG., Neumayer, E., Damania, R., Gates, S. 2005. Environmentalism, democracy, and pollution control. Journal of Environmental Economics and Management. 49, 343365.

Fredriksson, PG., Vollebergh, HR., Dijkgraaf, E. 2004. Corruption and energy efficiency in OECD countries: theory and evidence. Journal of Environmental Economics and Management. 47, 207-231.

Geys, B. \& Qari, S. 2017. Will you still trust me tomorrow? The causal effect of terrorism on social trust. Public Choice. In press (DOI 10.1007/s11127-017-0477-1).

Gómez-Limón, JA., Picazo-Tadeo, AJ., Reig-Martínez, E. 2012. Eco-efficiency assessment of olive farms in Andalusia'. Land Use Policy 29(2), 395-406.

Grafton, RQ., Knowles, S. 2004. Social capital and national environmental performance: a cross-sectional analysis. Journal of Environment and Development. 13, 336-370.

Guiso, L., Sapienza, P., Zingales, L. 2004. The role of social capital in financial development. American Economic Review. 94(3), 526-556.

Guiso, L., Sapienza, P., \& Zingales, L. 2008. Social capital as good culture. Journal of the European Economic Association, 6, 295-320.

Hailu A., Veeman T. 2001. Non-parametric productivity analysis with undesirable outputs: an application to the Canadian pulp and paper industry. American Journal of Agricultural Economics. 83, 605-616.

Halkos, GE., Jones, N. 2012. Modeling the effect of social factors on improving biodiversity protection. Ecological Economics. 78, 90-99.

Hanifan, LJ. 1916. The rural school community center. The Annals of the American Academy of Political and Social Science. 67, 130-138. 
Heineck, G., Süssmuth, B. 2013. A different look at Lenin's legacy: Social capital and risk taking in the two Germanies. Journal of Comparative Economics. 41(3), 789-803.

Ibrahim, MH., Law, SH. 2014. Social capital and CO 2 emission-output relations: a panel analysis. Renewable and Sustainable Energy Review. 29, 528-534.

Ingold, K. 2017. How to create and preserve social capital in climate adaptation policies: A network approach. Ecological Economics. 131, 414-424.

Jones, N. 2010. Investigating the influence of social costs and benefits of environmental policies through social capital theory. Policy Science. 43, 229-244.

Keene, A., Deller, SC. 2015. Evidence of the environmental Kuznets' curve among US counties and the impact of social capital. International Regional Science Review. 38(4), 358-387.

Knack, S., Keefer, P. 1997. Does social capital have an economic payoff? A cross country investigation. Quarterly Journal of Economics. 112(4), 1251-1288.

Kountouris, Y., Remoundou, K. 2016. Cultural influence on preferences and attitudes for environmental quality. Kyklos. 69(2), 369-397.

Korhonen, PJ., Luptacik, M. 2004. Eco-efficiency analysis of power plants: an extension of data envelopment analysis. European Journal of Operational Research. 154, 437-446.

Kortelainen, M. (2008). Dynamic environmental performance analysis: a Malmquist index approach. Ecological Economics. 64, 701-715.

Kuosmanen, T., Kortelainen M. 2005. Measuring eco-efficiency of production with Data Envelopment Analysis. Journal of Industrial Ecology. 9, 59-72.

Leitao, A. 2010. Corruption and the environmental Kuznets Curve: Empirical evidence for sulphur. Ecological Economics. 69, 2191-2201.

Liu, J., Qu, H., Huang, D., Chen, G., Yue, X., Zhao, X., Liang, Z. 2014. The role of social capital in encouraging residents' pro-environmental behaviors in community-based ecotourism. Tourism Management. 41, 190-201.

Nunn, N., Wantchekon, L. 2011. The slave trade and the origins of mistrust in Africa. American Economic Review. 101(7), 3221-52.

OECD 1998. Eco-efficiency, OECD, Paris.

OECD 2001. The Well-being of Nations: The Role of Human and Social Capital. OECD, Paris.

Onel, N., Mukherjee, A. 2014. The effects of national culture and human development on environmental health. Environment, Development and Sustainability. 16, 79-101. 
Paldam, M., Svendsen, GT. 2001. Missing social capital and the transition in Eastern Europe. Journal of Institutional Innovation, Development and Transition. 5, 21-34.

Park, H., Russell, C., Lee, J. 2007. National culture and environmental sustainability: A crossnational analysis. Journal of Economics and Finance. 31, 104-121.

Paudel, KP., Schafer, MJ. 2009. The environmental Kuznets curve under a new framework: the role of social capital in water pollution. Environmental and Resource Economics. 42, 265278.

Paxon, P. 2002. Social capital and democracy: an interdependent relationship. American Sociological Review. 67(2), 254-277.

Peiró-Palomino, J. 2016. Social capital and economic growth in Europe: Nonlinear trends and heterogeneous regional effects. Oxford Bulletin of Economics and Statistics. 78(5), 717751.

Peiró-Palomino, J., Tortosa-Ausina, E. 2015. Social capital, investment and economic growth: some evidence for Spanish provinces. Spatial Economic Analysis. 10, 102-126.

Peng, YS., Lin, SS. 2009. National culture, economic development, population growth and environmental performance: The mediating role of education. Journal of Business Ethics, 90, 203-219.

Picazo-Tadeo, AJ., Beltrán-Esteve, M., Gómez-Limón, JA. 2012. Assessing eco-efficiency with directional distance functions. European Journal of Operational Research. 220, 798-809.

Picazo-Tadeo, AJ., Castillo, J., Beltrán-Esteve, M. 2014. An intertemporal approach to measuring environmental performance with directional distance functions: greenhouse gas emissions in the European Union. Ecological Economics. 100, 173-182.

Picazo-Tadeo, AJ., Gómez-Limón, JA., Reig-Martínez, E. 2011. Assessing farming eco-efficiency: A Data Envelopment Analysis approach. Journal of Environmental Management 92(4), 1154-1164.

Polyzou, E., Jones, N., Evangelinos, K., Halvadakis, C. 2011. Willingness to pay for drinking water quality improvement and the influence of social capital. Journal of Socio-Economics. $40,74-80$.

Pretty, J. 2003. Social capital and the collective management of resources. American Association for the Advancement of Science, 302, 1912-1914.

Pretty, J., Ward, H. 2001. Social capital and the environment. World Development. 29, 209227. 
Putnam, R. 1993. Making Democracy Work: Civic Traditions in Modern Italy. Princeton University Press, New Jersey.

Rainer, H., Siedler, T. 2009. Does democracy foster trust? Journal of Comparative Economics. $37(2), 251-269$.

Rencher, A. 2002. Methods of Multivariate Analysis. 2nd edition. Wiley, New York.

Roth, F. 2009. Does too much trust hamper economic growth? Kyklos. 62(1), 103-128.

Simar, L., Wilson, PW. 2007. Estimation and inference in two-stage, semi-parametric models of production processes. Journal of Econometrics 136(1), 31-64.

Svendsen, GT., Svendsen, GLH. 2009. Handbook of Social Capital: The Troika of Sociology, Political Science and Economics, Edward Elgar Publishing, Cheltenham, UK.

Tabellini, G. 2008. Institutions and culture. Journal of the European Economic Association, 6, 905-950.

Tauchmann, H. 2016. Simarwilson: Stata module to perform Simar \& Wilson efficiency analysis. Statistical Software Components.

Torras, M., Boyce, JK. 1998. Income, inequality, and pollution: a reassessment of the environmental Kuznets curve. Ecological Economics. 25, 147-160.

Torsvik, G. 2000. Social capital and economic development. Rationality and Society. 12(4), 451476.

UN (United Nations) 2009. Eco-efficiency indicators: Measuring resource-use efficiency and the impact of economic activities on the environment. Greening of Economic Growth Series, ST/ESCAP/ 2561.

Uslaner, E. 2008. Where you stand depends upon where your grandparents sat. Public Opinion Quarterly. 72(4), 725-740.

Westlund, H., Larsson, JP., Olsson, AR. 2014. Start-ups and local entrepreneurial social capital in the municipalities of Sweden. Regional Studies. 48, 974-994.

Wursthorn, S., Poganietz, WR., Schebek, L., 2011. Economic-environmental monitoring indicators for European countries: a disaggregated sector-based approach for monitoring ecoefficiency. Ecological Economics. 70(3), 487-496.

Zak, P., Knack, S. 2001. Trust and growth. Economic Journal. 111, 295-321.

Zhang, B., Bi, J., Fan, Z., Yuan, Z., Ge, J. 2008. Eco-efficiency analysis of industrial system in China: a data envelopment analysis approach. Ecological Economics. 68, 306-316. 
Zukowski, R. 2007. Social capital and challenges of development in Latin America and East Central Europe. CESLA, Warsaw University, Warsaw. 
Table 1. - Descriptive statistics

$$
\text { Measurement unit }
$$

Mean

SD Maximum Minimum

ENVIRONMENTAL PERFORMANCE VARIABLES

Economic variable

Gross Domestic Product

1,000,000 constant 2011 \$US PPP

621,637

887,201

$3,466,284$

12,030

Environmental variables

Global warming potential

Tropospheric ozone formation potential

Acidification potential

Particulate formation potential

1,000 tons $\mathrm{CO}_{2}$ equivalents

1,000 tons NMVOC equivalents

1,000 tons $\mathrm{SO}_{2}$ equivalents

1,000 tons PM10 equivalents

$\begin{array}{rrrr}161,419 & 220,223 & 939,383 & 2,980 \\ 711 & 869 & 3,058 & 13 \\ 600 & 739 & 2,551 & 14 \\ 492 & 586 & 1,994 & 12\end{array}$

\section{SECOND-STAGE VARIABLES}

Social capital

Social trust

Association

Civic norms

Environmental policy

Stringency of environmental regulation

Enforcement of environmental regulation

Environmental treaties ratification

Legal and economic context

Government effectiveness

Regulatory quality

Control of corruption

R\&D expenditure

Quality of scientific institutions

Other variables

GDP per capita
Scale -2.5 to 2.5

Scale -2.5 to 2.5

Scale -2.5 to 2.5

$€$ per inhabitant

Scale 1 to 7

Constant 2011 thousands \$US PPP

$$
0.326
$$$$
0.033
$$$$
7.74
$$

0.178

0.041

1.49

0.760

0.232

8.62

0.092

0.007

7.08

5.07
4.66

4.66
23

1.29

1.36

4

1.13

1.17

0.97

486.0

4.81

33.4

$\begin{array}{rr}6.40 & 3.20 \\ 6.40 & 2.90 \\ 24 & 19\end{array}$

0.60

0.49

0.85

455.0

1.20

15.2 
Table 2. - Social capital indicators by country

\begin{tabular}{lrrr} 
& Social trust & Association & Civic norms \\
\hline Austria & 0.365 & 0.032 & 7.582 \\
Belgium & 0.351 & 0.032 & 7.682 \\
Bulgaria & 0.182 & 0.014 & 8.249 \\
Croatia & 0.197 & 0.014 & 7.558 \\
Cyprus & 0.092 & 0.018 & 7.401 \\
Czech Republic & 0.301 & 0.030 & 7.355 \\
Denmark & 0.760 & 0.232 & 8.443 \\
Estonia & 0.326 & 0.027 & 7.809 \\
Finland & 0.647 & 0.043 & 8.068 \\
France & 0.268 & 0.025 & 7.369 \\
Germany & 0.425 & 0.021 & 7.863 \\
Greece & 0.185 & 0.014 & 7.476 \\
Hungary & 0.221 & 0.009 & 8.004 \\
Ireland & 0.389 & 0.037 & 7.688 \\
Italy & 0.295 & 0.030 & 8.001 \\
Latvia & 0.255 & 0.024 & 7.280 \\
Lithuania & 0.299 & 0.016 & 7.078 \\
Luxembourg & 0.311 & 0.055 & 7.427 \\
Malta & 0.217 & 0.014 & 8.622 \\
Netherlands & 0.608 & 0.071 & 8.120 \\
Poland & 0.277 & 0.007 & 7.409 \\
Portugal & 0.172 & 0.024 & 8.020 \\
Romania & 0.174 & 0.019 & 7.560 \\
Slovakia & 0.126 & 0.014 & 7.253 \\
Slovenia & 0.242 & 0.040 & 7.875 \\
Spain & 0.335 & 0.010 & 7.640 \\
Sweden & 0.717 & 0.038 & 7.678 \\
United Kingdom & 0.381 & 0.021 & 8.198 \\
\hline
\end{tabular}


Table 3. - Factor analysis results for the first factor

\begin{tabular}{|c|c|c|c|c|}
\hline & \\
\hline & $\begin{array}{r}\text { First } \\
\text { eigenvalue }\end{array}$ & $\begin{array}{r}\text { Difference } \\
\text { with second } \\
\text { eigenvalue }\end{array}$ & $\begin{array}{r}\text { Proportion of } \\
\text { variance } \\
\text { explained }\end{array}$ & $\begin{array}{r}\text { Factor } \\
\text { loadings }\end{array}$ \\
\hline Social capital index & 1.342 & 1.407 & 0.447 & \\
\hline Social trust & & & & 0.741 \\
\hline Association & & & & 0.755 \\
\hline Civic norms & & & & 0.471 \\
\hline Environmental policy index & 1.951 & 1.952 & 0.650 & \\
\hline Stringency of environmental regulation & & & & 0.963 \\
\hline Enforcement of environmental regulation & & & & 0.965 \\
\hline Environmental treating ratification & & & & 0.303 \\
\hline Legal and economic context index & 4.072 & 4.070 & 0.814 & \\
\hline Government effectiveness & & & & 0.956 \\
\hline Regulatory quality & & & & 0.906 \\
\hline Control of corruption & & & & 0.982 \\
\hline R\&D expenditure & & & & 0.876 \\
\hline Quality of scientific institutions & & & & 0.775 \\
\hline
\end{tabular}

+ Factor analysis has been carried out with Stata 14.0 software. In order to avoid proportions larger than one due to the presence of negative eigenvalues, proportions have been computed using the trace of the correlation matrix as the divisor, instead of the sum of eigenvalues (see Rencher, 2002; pp.421-423). 
Table 4. - Spearman rank correlations with eco-efficiency

\begin{tabular}{rr}
\hline $\begin{array}{r}\text { Spearman } \\
\text { Significance } \\
\text { correlation }(r h o)\end{array}$ \\
level $(p$-value $)$
\end{tabular}

\begin{tabular}{lll}
\hline Social capital & & \\
Social trust & 0.519 & $0.004^{* * *}$ \\
Association & 0.406 & $0.031^{* *}$ \\
Civic norms & 0.217 & 0.265 \\
Environmental policy & & \\
Stringency of environmental regulation & 0.545 & $0.002^{* * *}$ \\
Enforcement of environmental regulation & 0.560 & $0.001^{* * *}$ \\
Environmental treaties ratification & 0.137 & 0.486 \\
Legal and economic context & & \\
Government effectiveness & 0.670 & $0.000^{* * *}$ \\
Regulatory quality & 0.583 & $0.001^{* * *}$ \\
Control of corruption & 0.651 & $0.000^{* * *}$ \\
R\&D expenditure & 0.697 & $0.000^{* * *}$ \\
Quality of scientific institutions & 0.659 & $0.000^{* * *}$ \\
\hline
\end{tabular}

${ }^{* *}$ and ${ }^{* * *}$ mean statistical significance at $5 \%$ and $1 \%$ confidence levels, respectively. 
Table 5. - Determinants of environmental performance

\begin{tabular}{|c|c|c|c|c|c|}
\hline \multirow[b]{2}{*}{ Dependent variable: eco-efficiency } & \\
\hline & Model 1 & Model 2 & Model 3 & Model 4 & Model 5 \\
\hline Constant & $\begin{array}{c}0.648^{* * *} \\
(0.039)\end{array}$ & $\begin{array}{l}0.649^{* * *} \\
(0.032)\end{array}$ & $\begin{array}{l}0.652^{* * *} \\
(0.030)\end{array}$ & $\begin{array}{c}0.651^{* * *} \\
(0.028)\end{array}$ & $\begin{array}{r}-0.303 \\
(0.278)\end{array}$ \\
\hline Social capital index & $\begin{array}{r}0.061 \\
(0.058)\end{array}$ & - & - & $\begin{array}{r}-0.057 \\
(0.048)\end{array}$ & $\begin{array}{r}-0.032 \\
(0.031)\end{array}$ \\
\hline Environmental policy index & - & $\begin{array}{l}0.092^{* * *} \\
(0.034)\end{array}$ & - & $\begin{array}{r}-0.068 \\
(0.076)\end{array}$ & $\begin{array}{r}-0.080 \\
(0.084)\end{array}$ \\
\hline Legal and economic context index & - & - & $\begin{array}{l}0.112^{* * *} \\
(0.032)\end{array}$ & $\begin{array}{c}0.206^{* *} \\
(0.083)\end{array}$ & $\begin{array}{r}0.013 \\
(0.086)\end{array}$ \\
\hline GDP per capita & - & - & - & - & $\begin{array}{c}0.043^{* * *} \\
(0.008)\end{array}$ \\
\hline GDP per capita squared & - & - & - & - & $\begin{array}{l}-0.0003^{* * *} \\
(0.0000)\end{array}$ \\
\hline Share of manufacturing in GVA & - & - & - & - & $\begin{array}{r}-0.213 \\
(0.579)\end{array}$ \\
\hline Sigma & $\begin{array}{l}0.169^{* * *} \\
(0.028)\end{array}$ & $\begin{array}{l}0.151^{* * *} \\
(0.024)\end{array}$ & $\begin{array}{l}0.139^{* * *} \\
(0.021)\end{array}$ & $\begin{array}{l}0.133^{* * *} \\
(0.020)\end{array}$ & $\begin{array}{l}0.087^{* * *} \\
(0.012)\end{array}$ \\
\hline Wald Chi ${ }^{2}$ & 1.125 & $7.276^{* \star *}$ & $11.772^{* \star *}$ & $15.637^{* * *}$ & $65.516^{* * *}$ \\
\hline
\end{tabular}

Number of bootstrap replications $=5,000$; standard errors in brackets.

${ }^{* *}$ and ${ }^{* * *}$ mean statistical significance at $5 \%$ and $1 \%$ confidence levels, respectively. 
Table 6. - Determinants of environmental performance: Estimations from the residuals ${ }^{+}$

\begin{tabular}{|c|c|c|c|c|c|}
\hline \multirow[b]{2}{*}{ Dependent variable: eco-efficiency } & \\
\hline & Model 6 & Model 7 & Model 8 & Model 9 & Model 10 \\
\hline Constant & $\begin{array}{l}0.643^{* * *} \\
(0.039)\end{array}$ & $\begin{array}{l}0.644^{* * *} \\
(0.037)\end{array}$ & $\begin{array}{c}0.646^{* * *} \\
(0.037)\end{array}$ & $\begin{array}{l}0.645^{* * *} \\
(0.037)\end{array}$ & $\begin{array}{c}-0.235^{*} \\
(0.136)\end{array}$ \\
\hline Residuals from social capital index & $\begin{array}{r}-0.005 \\
(0.053)\end{array}$ & - & - & $\begin{array}{r}-0.048 \\
(0.063)\end{array}$ & $\begin{array}{r}-0.032 \\
(0.031)\end{array}$ \\
\hline $\begin{array}{l}\text { Residuals from environmental policy } \\
\text { index }\end{array}$ & - & $\begin{array}{r}0.016 \\
(0.053)\end{array}$ & - & $\begin{array}{r}-0.072 \\
(0.098)\end{array}$ & $\begin{array}{r}-0.080 \\
(0.083)\end{array}$ \\
\hline $\begin{array}{l}\text { Residuals from legal and economic } \\
\text { context index }\end{array}$ & - & - & $\begin{array}{r}0.045 \\
(0.057)\end{array}$ & $\begin{array}{r}0.146 \\
(0.117)\end{array}$ & $\begin{array}{r}0.013 \\
(0.084)\end{array}$ \\
\hline GDP per capita & - & - & - & - & $\begin{array}{l}0.039^{* * *} \\
(0.006)\end{array}$ \\
\hline GDP per capita squared & - & - & - & - & $\begin{array}{l}-0.0003^{* * *} \\
(0.0000)\end{array}$ \\
\hline $\begin{array}{l}\text { Residuals from share of } \\
\text { manufacturing in GVA }\end{array}$ & - & - & - & - & $\begin{array}{r}-0.213 \\
(0.569)\end{array}$ \\
\hline Sigma & $\begin{array}{l}0.174^{* * *} \\
(0.029)\end{array}$ & $\begin{array}{l}0.174^{* * *} \\
(0.028)\end{array}$ & $\begin{array}{l}0.172^{* * *} \\
(0.028)\end{array}$ & $\begin{array}{l}0.168^{* * *} \\
(0.027)\end{array}$ & $\begin{array}{l}0.087^{* * *} \\
(0.012)\end{array}$ \\
\hline Wald Chi ${ }^{2}$ & 0.010 & 0.094 & 0.631 & 1.749 & $66.005^{* \star *}$ \\
\hline
\end{tabular}

Number of bootstrap replications $=5,000$; standard errors in brackets.

${ }^{*}$ and ${ }^{* * *}$ mean statistical significance at $10 \%$ and $1 \%$ confidence levels, respectively.

+ Residuals are obtained from OLS regressions of a constant and GDP per capita on each of the indexes, and the share of manufacturing in GVA. 
Table 7. - Comparison of social capital indicators from the 1999 and 2008 waves of the EVS ${ }^{+}$

\begin{tabular}{|c|c|c|c|}
\hline & \\
\hline & Social trust & Association & Civic norms $^{++}$ \\
\hline Spearman rank correlation test (rho) & $\begin{array}{c}0.844^{* * *} \\
(0.000)\end{array}$ & $\begin{array}{c}0.448^{* *} \\
(0.019)\end{array}$ & $\begin{array}{l}0.505^{* * *} \\
(0.007)\end{array}$ \\
\hline $\begin{array}{l}\text { Kolmogorov-Smirnov test of the } \\
\text { equality of distributions }{ }^{+++}(\text {KS-statistic) }\end{array}$ & $\begin{array}{r}0.185 \\
(0.754)\end{array}$ & $\begin{array}{r}0.259 \\
(0.329)\end{array}$ & $\begin{array}{r}0.333 \\
(0.101)\end{array}$ \\
\hline
\end{tabular}

${ }^{* *}$ and ${ }^{* * *}$ mean statistical significance at $5 \%$ and $1 \%$ confidence levels, respectively; p-values in brackets.

+ Due to lack of data in the 1999 EVS, Cyprus is not included in the analysis

++ In the 1999 EVS, the civic norms indicator is built based on only three elements: (i) claiming state benefits to which one is not entitled; (ii) cheating on tax; and (iii) accepting a bribe. In any case, the correlation between the 2008 EVS civic norms indicator based on only these three elements and the one that incorporates all four available elements (which we use in this paper) is above 0.99, and significant at the $1 \%$ level.

${ }^{+++}$The null hypothesis is that indicators, i.e., social trust/association/civic norms, in both the 1999 and 2008 waves of the EVS have the same distribution. 
Figure 1. - Social capital index in the European Union ${ }^{+}$

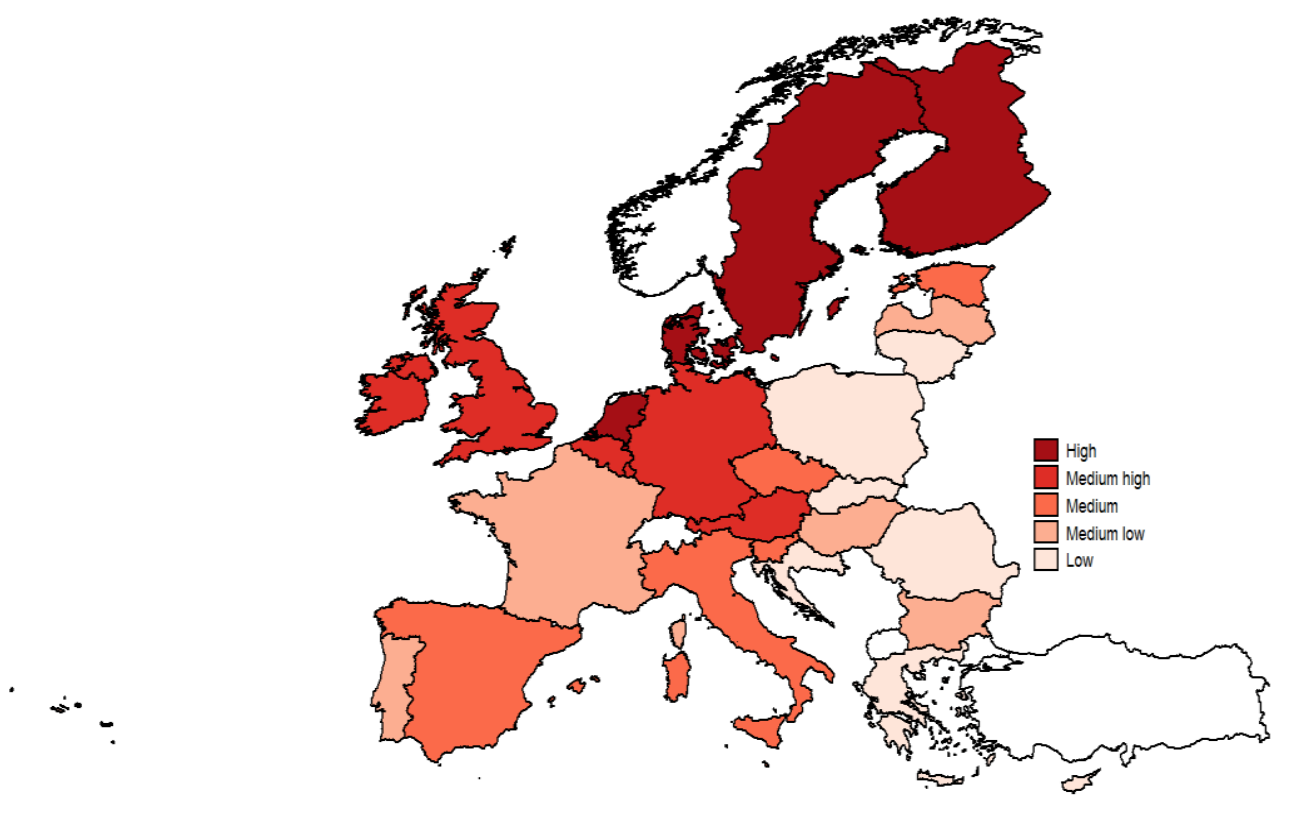

+ Categories correspond to quintiles (low and high are $1^{\text {st }}$ and $5^{\text {th }}$ quintiles, respectively) of the composed social capital index. 
Figure 2. - Environmental performance in the European Union ${ }^{+}$

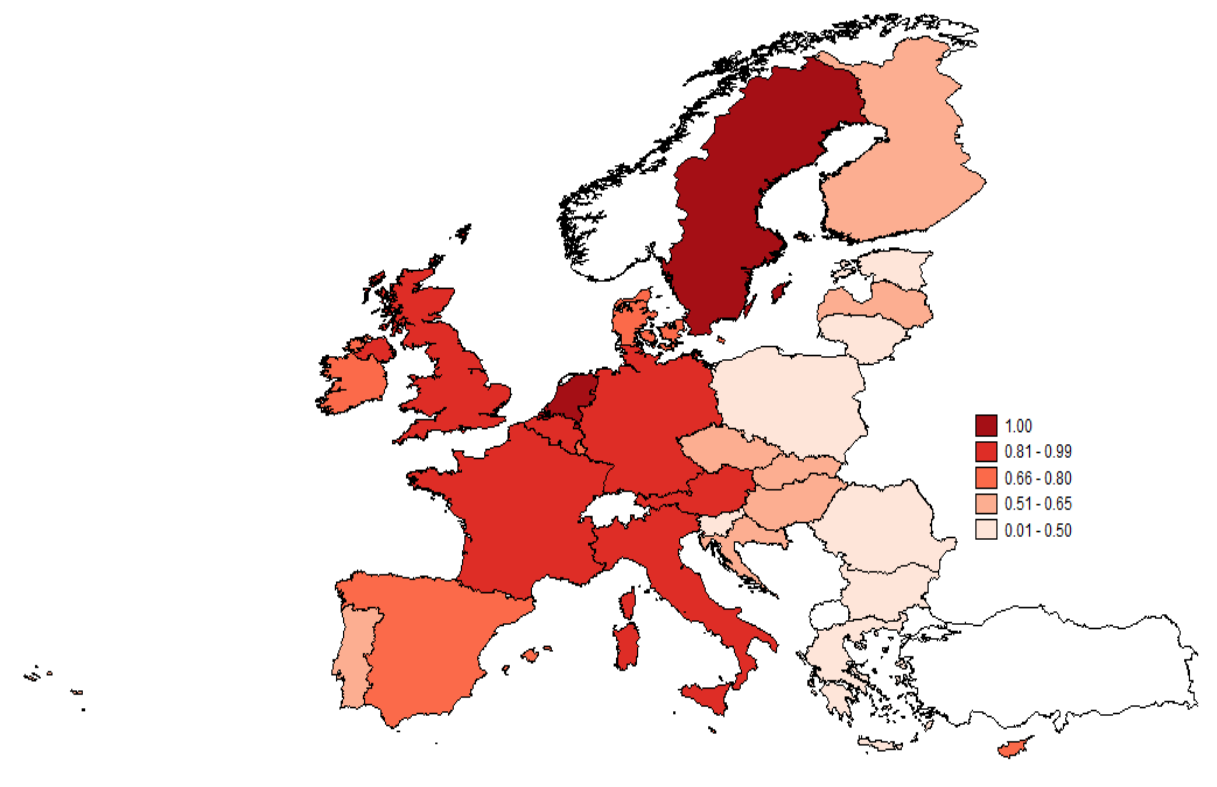

+ Categories correspond to eco-efficiency intervals, with a value of 1 representing fully eco-efficient countries. 


\section{APPENDIX 1}

Conversion factors used to translate figures on individual pollutants into environmental pressures (Measurement unit in parentheses).

\section{Conversion factor}

Global warming potential ( $\mathrm{CO}_{2}$ equivalents)

Greenhouse gases (GHGs) ${ }^{++}$

Tropospheric ozone formation potential (NMVOC equivalents)

Non-methane volatile organic components (NMVOC)

Carbon monoxide $(\mathrm{CO})$

Nitrogen oxides $\left(\mathrm{NO}_{x}\right)$

Methane $\left(\mathrm{CH}_{4}\right)$

Acidification potential ( $\mathrm{SO}_{2}$ equivalents)

Sulphur dioxide $\left(\mathrm{SO}_{2}\right)$

1

Nitrogen oxides $\left(\mathrm{NO}_{x}\right)$

Ammonia $\left(\mathrm{NH}_{3}\right)$

Particulate formation potential (PM10 equivalents)

Primary particulate matter (PM10)

Nitrogen oxides $\left(\mathrm{NO}_{x}\right)$

Sulphur dioxide $\left(\mathrm{SO}_{2}\right)$

+ These conversion factors were obtained from de Leeuw (2002). Also note that some of these pollutants might cause more than one environmental pressure; e.g., $\mathrm{SO}_{2}$ or $\mathrm{NO}_{x}$.

${ }_{+}^{++}$Greenhouse gases include carbon dioxide $\left(\mathrm{CO}_{2}\right)$, nitrous oxide $\left(\mathrm{N}_{2} \mathrm{O}\right)$, methane $\left(\mathrm{CH}_{4}\right)$, sulphur hexafluoride $\left(S F_{6}\right)$, hydrofluorocarbons (HFCs) and perfluorocarbons (PFCs); figures on aggregate emissions of GHGs in $\mathrm{CO}_{2}$ equivalents have been directly obtained from the Greenhouse Gases Inventory of the European Environment Agency. 


\section{APPENDIX 2}

Variables: description and sources

\begin{tabular}{|c|c|c|}
\hline Variable & Description & Source \\
\hline \multicolumn{3}{|l|}{ ENVIRONMENTAL PERFORMANCE } \\
\hline \multicolumn{3}{|l|}{ Economic variable } \\
\hline Gross Domestic Product & $\begin{array}{l}\text { GDP in constant } \$ \text { US at } 2011 \text { prices in purchasing power parity (PPP); } \\
1,000,000 \$ \text { US. Average } 2012-13 \text {. }\end{array}$ & $\begin{array}{l}\text { World Development Indicators - World } \\
\text { Bank (WB) }\end{array}$ \\
\hline \multicolumn{3}{|l|}{ Environmental variables } \\
\hline Global warming potential & $\begin{array}{l}\mathrm{CO}_{2} \text { equivalents released into the environment; } 1,000 \text { tons. Average } \\
2012-13 \text {. }\end{array}$ & $\begin{array}{l}\text { Greenhouse Gases Inventory - European } \\
\text { Environment Agency (EEA) }\end{array}$ \\
\hline $\begin{array}{l}\text { Tropospheric ozone formation } \\
\text { potential }\end{array}$ & $\begin{array}{l}\text { NMVOC (non-methane volatile organic compound) equivalents } \\
\text { released into the environment; 1,000 tons. Average 2012-13. }\end{array}$ & $\begin{array}{l}\text { National emissions reported to the LRTAP } \\
\text { Convention - EEA }\end{array}$ \\
\hline Acidification potential & $\begin{array}{l}\mathrm{SO}_{2} \text { equivalents released into the environment; } 1,000 \text { tons. Average } \\
2012-13 \text {. }\end{array}$ & $\begin{array}{l}\text { National emissions reported to the LRTAP } \\
\text { Convention - EEA }\end{array}$ \\
\hline Particulate formation potential & $\begin{array}{l}\text { PM10 (particulate matter) equivalents released into the environment; } \\
\text { 1,000 tons. Average 2012-13. }\end{array}$ & $\begin{array}{l}\text { National emissions reported to the LRTAP } \\
\text { Convention - EEA }\end{array}$ \\
\hline \multicolumn{3}{|l|}{ SECOND-STAGE } \\
\hline \multicolumn{3}{|l|}{ Social capital } \\
\hline Social trust & $\begin{array}{l}\text { Affirmative responses to the question 'Generally speaking, would you say } \\
\text { that most people can be trusted or that you can't be too careful in dealing with } \\
\text { people?'; percentage. Year } 2008 \text {. }\end{array}$ & European Values Study (EVS) \\
\hline Association & $\begin{array}{l}\text { Affirmative responses to the question 'Do you work unpaid for...?' } \\
\text { including } 15 \text { different associations; percentage. Year } 2008 .\end{array}$ & EVS \\
\hline Civic norms & $\begin{array}{l}\text { Average score: 'Do you consider that the following actions are justified?' (i) } \\
\text { claiming state benefits to which one is not entitled; (ii) cheating on tax; (iii) } \\
\text { accepting a bribe; and (iv) avoiding fares in public transport; scale 1-10. Year } \\
2008 \text {. }\end{array}$ & EVS \\
\hline
\end{tabular}




\begin{tabular}{|c|c|c|}
\hline Variable & Description & Source \\
\hline \multicolumn{3}{|l|}{ Environmental policy } \\
\hline $\begin{array}{l}\text { Stringency of environmental } \\
\text { regulation }\end{array}$ & $\begin{array}{l}\text { Assessment of countries' overall environmental regulation stringency (higher } \\
\text { score = more stringent); scale 1-7. Average 2011-12. }\end{array}$ & $\begin{array}{l}\text { Executive Opinion Survey - World } \\
\text { Economic Forum (WEF) }\end{array}$ \\
\hline $\begin{array}{l}\text { Enforcement of environmental } \\
\text { regulation }\end{array}$ & $\begin{array}{l}\text { Assessment of countries' enforcement of overall environmental regulation } \\
\text { (higher score = more rigorous); scale 1-7. Average 2011-12. }\end{array}$ & Executive Opinion Survey - WEF \\
\hline $\begin{array}{l}\text { Environmental treaties } \\
\text { ratification }\end{array}$ & Total number of ratified international environmental treaties. Year 2012. & Executive Opinion Survey - WEF \\
\hline \multicolumn{3}{|l|}{ Legal and economic context } \\
\hline Government effectiveness & $\begin{array}{l}\text { Perceptions of the quality of public services, the civil service and the degree of its } \\
\text { independence from political pressures, the quality of policy formulation and } \\
\text { implementation, and the credibility of government's commitment to such policies } \\
\text { (higher score = more effective); scale }-2.5 \text { to } 2.5 \text {. Average } 2012-13 \text {. }\end{array}$ & $\begin{array}{l}\text { Worldwide Governance Indicators } \\
\text { (WGI) project - WB }\end{array}$ \\
\hline Regulatory quality & $\begin{array}{l}\text { Perceptions of the ability of the government to formulate and implement sound } \\
\text { policies and regulations that permit and promote private sector development } \\
\text { (higher score = better quality); scale }-2.5 \text { to } 2.5 \text {. Average 2012-13. }\end{array}$ & WGI project - WB \\
\hline Control of corruption & $\begin{array}{l}\text { Perceptions of the extent to which public power is exercised for private gain, as } \\
\text { well as 'capture' of the state by elites and private interests (higher score = more } \\
\text { control); scale }-2.5 \text { to } 2.5 \text {. Average } 2012-13 \text {. }\end{array}$ & WGI project - WB \\
\hline R\&D expenditure & Total expenditure on R\&D in $€$ per inhabitant. Average 2012-13. & Eurostat \\
\hline Quality of scientific institutions & $\begin{array}{l}\text { Assessment of the quality of countries' scientific research institutions (higher } \\
\text { score = better quality); scale } 1 \text { to } 7 . \text { Average } 2012-13 \text {. }\end{array}$ & Executive Opinion Survey - WEF \\
\hline \multicolumn{3}{|l|}{ Other variables } \\
\hline GDP per capita & GDP in constant thousands 2011 \$US PPP per inhabitant. Average 2012-13. & World Development Indicators - WB \\
\hline $\begin{array}{l}\text { Share of manufacturing in } \\
\text { Gross Value Added (GVA) }\end{array}$ & GVA of manufacturing over aggregate GVA, in percentage. Average 2012-13. & AMECO - European Commission \\
\hline
\end{tabular}




\section{APPENDIX 3}

Determinants of environmental performance with data on social capital from the 1999 EVS $^{+}$

\begin{tabular}{|c|c|c|c|}
\hline & & & \\
\hline Dependent variable: eco-efficiency & Model 1' & Model $4^{\prime}$ & Model 5' \\
\hline Constant & $\begin{array}{c}0.649^{* * *} \\
(0.040)\end{array}$ & $\begin{array}{c}0.654^{* * *} \\
(0.030)\end{array}$ & $\begin{array}{r}-0.319 \\
(0.300)\end{array}$ \\
\hline Social capital index from the 1999 EVS & $\begin{array}{r}0.003 \\
(0.063)\end{array}$ & $\begin{array}{r}-0.002 \\
(0.049)\end{array}$ & $\begin{array}{r}0.018 \\
(0.030)\end{array}$ \\
\hline Environmental policy index & - & $\begin{array}{r}-0.064 \\
(0.088)\end{array}$ & $\begin{array}{r}-0.056 \\
(0.085)\end{array}$ \\
\hline Legal and economic context index & - & $\begin{array}{c}0.173^{*} \\
(0.092)\end{array}$ & $\begin{array}{r}-0.037 \\
(0.080)\end{array}$ \\
\hline GDP per capita & - & - & $\begin{array}{c}0.044^{* * *} \\
(0.009)\end{array}$ \\
\hline GDP per capita squared & - & - & $\begin{array}{l}-0.0003^{* * *} \\
(0.0000)\end{array}$ \\
\hline Share of manufacturing in GVA & - & - & $\begin{array}{r}-0.304 \\
(0.592)\end{array}$ \\
\hline Sigma & $\begin{array}{l}0.177^{* * *} \\
(0.031)\end{array}$ & $\begin{array}{l}0.141^{* * *} \\
(0.022)\end{array}$ & $\begin{array}{l}0.090^{* * *} \\
(0.013)\end{array}$ \\
\hline Wald Chi ${ }^{2}$ & 0.004 & $11.754^{* * *}$ & $55.841^{* * *}$ \\
\hline
\end{tabular}

Number of bootstrap replications $=5,000 ;$ standard errors in brackets.

${ }^{*}$ and ${ }^{* * *}$ mean statistical significance at $10 \%$ and $1 \%$ confidence levels, respectively.

+ Models 2 and 3 have not been re-estimated, as they do not include social capital as an explanatory variable of eco-efficiency. Furthermore, Cyprus is not included in the regression due to lack of data on social capital in the 1999 EVS. 


\section{APPENDIX 4}

Determinants of environmental performance using social trust as a single measure of social capital ${ }^{+}$

\begin{tabular}{|c|c|c|c|c|c|c|}
\hline \multirow{3}{*}{ Dependent variable: eco-efficiency } & \\
\hline & \multicolumn{3}{|c|}{ Social trust from the 2008 EVS } & \multicolumn{3}{|c|}{ Social trust from the 1999 EVS } \\
\hline & Model 1'” & Model $4^{\prime \prime}$ & Model 5” & Model $1^{\prime \prime \prime}$ & Model $4^{\prime \prime \prime}$ & Model 5'”' \\
\hline Constant & $\begin{array}{c}0.534^{* * *} \\
(0.083)\end{array}$ & $\begin{array}{l}0.780^{* * *} \\
(0.101)\end{array}$ & $\begin{array}{r}-0.251 \\
(0.272)\end{array}$ & $\begin{array}{l}0.650^{* * *} \\
(0.090)\end{array}$ & $\begin{array}{l}0.657^{* * *} \\
(0.070)\end{array}$ & $\begin{array}{r}-0.316 \\
(0.298)\end{array}$ \\
\hline Social trust & $\begin{array}{r}0.363 \\
(0.267)\end{array}$ & $\begin{array}{r}-0.412 \\
(0.315)\end{array}$ & $\begin{array}{c}-0.288 \\
(0.208)\end{array}$ & $\begin{array}{r}-0.002 \\
(0.256)\end{array}$ & $\begin{array}{r}-0.009 \\
(0.200)\end{array}$ & $\begin{array}{r}0.017 \\
(0.124)\end{array}$ \\
\hline Environmental policy index & - & $\begin{array}{r}-0.032 \\
(0.079)\end{array}$ & $\begin{array}{c}-0.068 \\
(0.081)\end{array}$ & - & $\begin{array}{r}-0.064 \\
(0.088)\end{array}$ & $\begin{array}{r}-0.060 \\
(0.085)\end{array}$ \\
\hline Legal and economic context index & - & $\begin{array}{c}0.187^{* *} \\
(0.078)\end{array}$ & $\begin{array}{r}0.017 \\
(0.082)\end{array}$ & - & $\begin{array}{c}0.173^{*} \\
(0.091)\end{array}$ & $\begin{array}{r}-0.032 \\
(0.081)\end{array}$ \\
\hline GDP per capita & - & - & $\begin{array}{l}0.043^{* * *} \\
(0.008)\end{array}$ & - & - & $\begin{array}{c}0.044^{* * *} \\
(0.009)\end{array}$ \\
\hline GDP per capita squared & - & - & $\begin{array}{l}-0.0003^{* * *} \\
(0.0000)\end{array}$ & - & - & $\begin{array}{l}-0.0003^{* * *} \\
(0.0000)\end{array}$ \\
\hline Share of manufacturing in GVA & - & - & $\begin{array}{c}-0.107 \\
(0.575)\end{array}$ & - & - & $\begin{array}{c}-0.287 \\
(0.598)\end{array}$ \\
\hline Sigma & $\begin{array}{l}0.167^{* * *} \\
(0.027)\end{array}$ & $\begin{array}{c}0.132^{* * *} \\
(0.020)\end{array}$ & $\begin{array}{l}0.086^{\text {*** }} \\
(0.012)\end{array}$ & $\begin{array}{l}0.177^{* * *} \\
(0.031)\end{array}$ & $\begin{array}{l}0.141^{* * *} \\
(0.022)\end{array}$ & $\begin{array}{l}0.091^{* * *} \\
(0.013)\end{array}$ \\
\hline Wald Chi ${ }^{2}$ & 1.844 & $15.179^{* * *}$ & $65.652^{* * *}$ & 0.000 & $11.954^{* * *}$ & $55.786^{* * *}$ \\
\hline
\end{tabular}

Number of bootstrap replications $=5,000$; standard errors in brackets.

** and *** mean statistical significance at $5 \%$ and $1 \%$ confidence levels, respectively.

+ Models 2 and 3 have not been re-estimated, as they do not include social capital as an explanatory variable of eco-efficiency. Furthermore, Cyprus is not included in Models 1"', 4"' and 5"' due to lack of data on social trust in the 1999 EVS. 